\title{
Dactylogyrus dulkeiti Bychowsky, 1936 (Monogenea: Dactylogyride): first occurrence on the gills of Carassius auratus Linnaeus, 1758 from Dukan Lake in Kurdistan Region, Iraq
}

\author{
Younis S. Abdullah ${ }^{1 *}$ and Shamall M. A. Abdullah ${ }^{1,2}$ \\ ${ }^{1}$ Department of Medical Laboratory, Sulaimani Polytechnic University, Sulaimani, Kurdistan Region, Iraq. \\ ${ }^{2}$ Department of Fish Resource and Aquatic Animal, Salahaddin University, Erbil, Kurdistan Region, Iraq. \\ *Corresponding Author: younis.abdullah@spu.edu.iq
}

Received | December 28, 2015

Accepted | February 02, 2016

\begin{abstract}
This study presents the first record of the monogenean parasite Dactylogyrus dulkeiti Bychowsky, 1936 on gill filaments of the crucian carp Carassius auratus in the Kurdistan Region of Iraq. Fifty two fishes were collected from Dukan Lake that is located in the northwest of Sulaimani City from April to the end of July 2015. The prevalence of this parasite was $\mathbf{7 . 6 9 \%}$ and the mean of intensity was 8.5 . The description and measurement of this parasite has been discussed in details in the current work. The aim of the study is to indicate the parasitic fauna of an exotic species of fish that introduced in Dukan Lake in Kurdistan Region of Iraq.
\end{abstract}

Key words: Dactylogyrus dulkeiti, Carassius auratus, Dukan Lake, Kurdistan region, Iraq.

\section{Introduction}

It has been estimated that nearly 53 species of freshwater fishes inhabit Iraqi territory. Among them, approximately nine species of fish considered to be imported to the freshwater of Iraq (Coad, 2010). Carassius auratus is one of those exotic freshwater species that introduced into the Iraqi freshwater, the native distribution is in northern Asia and China (Coad, 2010). C. auratus Linnaeus, (1758) has been widely introduced to garden ponds and released from aquaria in temperate to warm waters worldwide including Iraq. Monogenea are permanent ectoparasites on the body surface or gills of marine, brackish, or fresh water fishes and in rare cases are exist as endoparasites in nasal cavities, ureters, urinary bladder, or alimentary canal of fishes, amphibians, reptiles, or mammals (Margolis and Kabata, 1984). The most important monogenean parasites (flukes) in fish are the dactylogyrids and gyrodactylids (Amlacher, 1970).

Dactylogyrus causes irritation, excessive mucus production and create portals for entry for bacterial invasion (Reed et al., 1996). The genus Dactylogyrus from Iraqi freshwater fish was first described by Ali et al. (1986).

This study describes monogenean Dactylogyrus dulkeiti from the gill of $C$. auratus (Family: Cyprinidae) which has not been recorded before in Kudistan Region of Iraq. This parasite was caught 
in the Dukan Lake located in the northwest of

Sulaimany City of Kurdistan Region of Iraq.

\section{Materials and Methods}

Study area: Dukan Lake is the largest lake in the Iraqi Kurdistan Region. It's located about 65 km northwest of Sulaimaniy City, in the north of Kurdistan Region-Iraq. It is situated $34^{\circ} .5^{-}$ $36^{\circ} .3^{-}$north latitude and $43^{\circ} .17^{-}-46^{\circ} .24^{-}$east longitude, at an altitude of $511 \mathrm{~m}$ of the sea level. The surface area is between $48-270 \mathrm{~km}^{2}$ and the lake capacity is $6.8 \times 10 \mathrm{~m}^{3}$ (Abdullah, 2009).

Sampling: A total of 52 C. auratus were collected from Dukan Lake, by local fishermen using gill netting twice monthly during the period from April to the end of July 2015. The fishes were placed in a cool box with the local lake water, and transferred immediately to the laboratory as soon as possible and were examined within 24 hours after their capture. The fishes were identified according to Coad (2010).

In the laboratory, the gill arches from both sides were separated, kept moist in Petri dish examined under dissecting microscope for counting Dactylogyrus on each gill lamella, which were stained by aqueous neutral red, and permanent slides were prepared with glycerol-gelatin (Gussev, 1993). Photos were taken by Sony Optical Steady Shot Digital camera model DSCW570, 16.1 megapixels. The measurements of parasites were achieved by ocular micrometer, and the terminology was used as recommended by Pugachev et al. (2010). The parasite identification and the terms were used as recommended by Pugachev et al. (2010) and BykhovskayaPavlovskaya et al. (1962).

\section{Results}

C. auratus were surveyed for parasitic monogenean in the present study. The survey showed the occurrence of one monogenean that belongs to the genus Dactylogyrus. The following is a brief account of this parasite as shown in (Figure 1):

Host: Carassius auratus Linnaeus, 1758

Site infection: Gill filaments

Percentage incidence of infection: $7.69 \%$

Mean of intensity: 8.5

Description: Small worms, total length 0.32-0.52 $\mathrm{mm}$, width $0.07-0.15 \mathrm{~mm}$. The length of marginal hooks $0.018-0.025 \mathrm{~mm}$. The total length of median hook 0.045-0.055 mm. connecting bar 0.002$0.003 \times 0.025-0.037 \mathrm{~mm}$. Total length of the copulatory organ $0.020-0.030 \mathrm{~mm}$. Tube of the copulatory organ with slightly expanded root, supporting plate with straight handle, expanded spatulate terminally. Tube of copulatory organ thin-walled, terminal expansion of supporting plate flat, plate is crescent shaped (BykhovskayaPavlovskaya et al. (1962).

\section{Discussion}

The description and measurements of the present specimens are similar to those reported by Bykhovskaya-Pavlovskaya et al. (1962) detected on gill filaments of golden and silver crucian carps from basins of Caspian and White (Sukhona river) seas, waters of Kazakhstan (lake Kurgal'dzhin), western Siberia (Barabinskie lake) and far east (Table 1). 


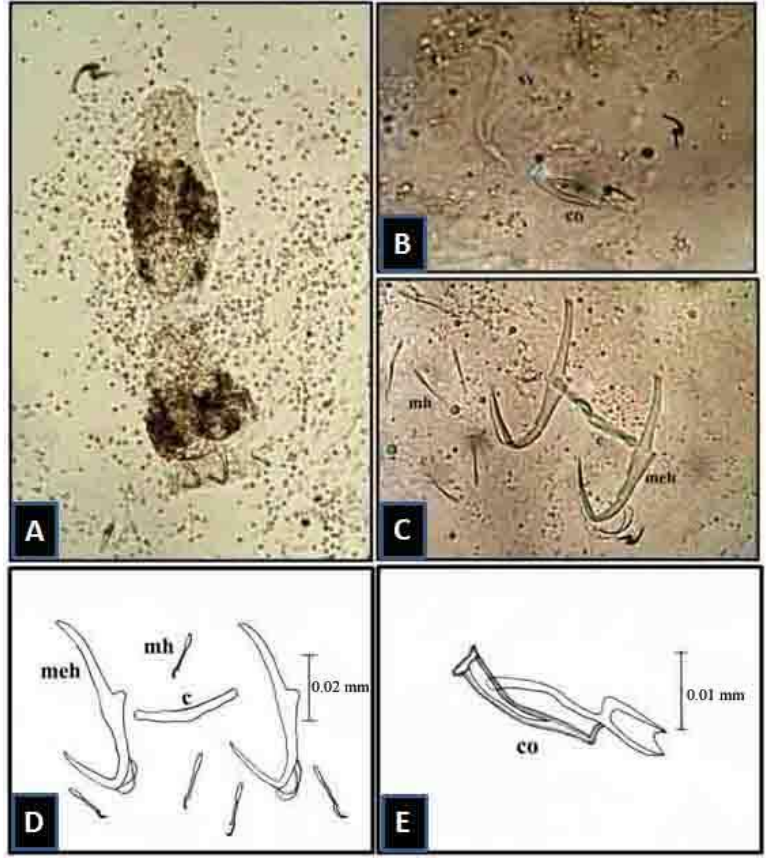

Figure 1: Dactylogyrus dulkeiti. A) Photomicrograph of the worm (100x). B) Photomicrograph of the worm's copulatory organ (600x). C) Photomicrograph of the haptor (500x). D) Camera lucida drawing of the haptor. E) Camera lucida drawing of the copulatory organ. c, connecting bar; co, copulatory organ; meh, median hook; mh, marginal hook; sv, seminal vesicle.

D. dulkeiti Bychowsky, 1936 has been recorded for the first time in Iraq from Cyprinus carpio from Al-Zaafaraniya fish farm in Baghdad (Mohammad-Ali et al., 1999). After that, it was reported from four different fish hosts (Barbus sharpeyi, Carassius auratus, Carassius carassius and Chondrostoma region (Mhaisen, 2015). The present monogenean shows a great similarity to the specimens which were recorded previously in Iraq. Since, there is no any previous report about recording this species in Kurdistan Region, the present record represents the first record of $D$. dulkeiti in this region.

A total of 78 species of Dactylogyrus were known from different species of fishes in Iraq. Among this number, 49 species were recorded in
Kurdistan Region and most of them were found on gills of cyprinid fishes (Mhaisen, 2015).

Table 1: Comparison between the measurements of the present specimens of Dactylogyrus dulkeiti with that previously reported from the same host.

\begin{tabular}{|l|c|c|}
\hline \multicolumn{1}{|c|}{$\begin{array}{c}\text { Parameters } \\
\text { (mm.) }\end{array}$} & Our results & $\begin{array}{c}\text { Bykhovskaya- } \\
\text { Pavlovskaya } \text { et al. }, \\
\mathbf{( 1 9 6 2 )}\end{array}$ \\
\hline Total Length & $0.320-0.520$ & 0.360 \\
\hline Total Width & $0.070-0.150$ & 0.070 \\
\hline Marginal hooks & $0.018-0.025$ & $0.015-0.026$ \\
\hline Median hooks & $0.045-0.055$ & $0.015-0.057$ \\
\hline Connecting bar & $0.025-0.037$ & $0.024-0.037$ \\
\hline Copulatory organ & $0.020-0.030$ & $0.020-0.029$ \\
\hline
\end{tabular}

\section{Conclusions}

During the external examination for the gill filaments of $C$. auratus the monogenean trematode (Dactylogyrus dulkeiti) is recorded for the first time in the present study in the Kurdistan Region. The fishes were collected from Dukan Lake in the northwest of Sulaimany city in Kurdistan Region of Iraq. The prevalence of infection and the mean of intensity were $7.69 \%$ and 8.5 respectively.

\section{Acknowledgment}

The authors wish to thanks Professor Dr. Furhan T. Mhaisen for his help in providing useful references and materials.

\section{References}

Abdullah, S. M. A. (2009). Neoechinorhynchus zabensis (Acanthocephala: Neoechinorhynchidae) in Capoeta damascina and C. trutta (Osteichthyes: Cyprinidae) from Dokan Lake and Greater Zab River, Northern Iraq. Jordan J. of Agric. Sci., 5(1), 38-48. 
Ali, N. M., Al-Jafery, A. R., Abdul-Ameer, K. N. (1986). New records of three monogenetic trematodes on some freshwater fishes from Diyala river, Iraq. J. Biol. Sci. Res., 17(2), 253-266.

Amlacher, E. (1970). Textbook of fish diseases. Engl. Transl. T.F.H. Publ., Jersey City, 302 Pp.

Bykhovskaya-Pavlovskaya, I. E., Gusev, A. V., Dubinia, M. N., Izyumova, N. A., Smirnova, T. S., Sokolovskaya, I. L., Shtein, G. A., Shul'man, S. S., Epshtein, V. M. (1962). Key to parasites of freshwater fish of the U. S. S. R. Akad. Nauk, S. S. S. R., Moscow, (In Russian).

Coad, B. W. (2010). Freshwater fishes of Iraq. Pensoft Publisher, Sofia-Moscow.

Gussev, A. V., Ali, N. M., Abdul-Ameer, K. N., Amin, S. M., Molnár, K. (1993). New and known species of Dactylogyrus Diesing, 1850 (Monogenea, Dactylogyridae) from cyprinid fishes of the river Tigris, Iraq. Syst. Parasitol., 25, 229-237.

Margolis, L., Kabata Z. (1984). Guide to the parasites of the fishes of Canada part I. National printers press, (Ottawa) Canada Inc, $209 \mathrm{Pp}$.

Mhaisen, F. T. (2015). Index-catalogue of parasites and diseases agents of fishes of Iraq. Unpuble. (Personal communication)

Mohammad-Ali, N. R., Balasem, A. N., Mhaisen, F. T., Salih, A. M., Waheed, I. K. (1999). Observation on the parasitic fauna in Al- Zaafaraniya fish farm, south of Baghdad. Vet. 9(2), 79-88.

Pugachev, O. N., Gerasev, P. I., Gussev, A. V., Ergens, R., Khotenowsky, I. (2010). Guide to monogenoidea of freshwater fish of Palaeartic and Amur regions. Ledizioni Ledipublishing, Milano: $567 \mathrm{pp}$

Reed, P., Francis-Floyd, R., Klinger, R. E., Petty, D. (1996). Monogenean parasites of fish. Institute of Food and Agricultural Sciences, University of Florida, FA28: 10pp. 